Muschalla, B., Fay, D., \& Seemann, A. (2016). Asking for work adjustments or initiating behavioral changes - what makes a "problematic co-worker" score Brownie points? An experimental study on the reactions towards colleagues with a personality disorder. Psychology, Health, \& Medicine, 21, 856-862.

Asking for work adjustments or initiating behavioural changes - what makes a "problematic co-worker" score Brownie points? An experimental study on the reactions towards colleagues with a personality disorder

Running head: reactions towards personality disorders at work

Original Article for publication in: Psychology, Health \& Medicine

Authors: Beate Muschalla, Doris Fay, Anne Seemann

Work and Organizational Psychology, University of Potsdam, Potsdam, Germany

1492 words (manuscript text excluding abstract and references), 3 tables

There was no financial support for this study from any institution.

Correspondence address: Beate Muschalla, University Potsdam, Work and

Organizational Psychology, Karl-Liebknecht-Str. 24-25, 14476 Potsdam,

Germany, Email: beate.muschalla@gmx.de 


\title{
Asking for work adjustments or initiating behavioural changes - what makes a "problematic co-worker" score Brownie points? An experimental study on the reactions towards colleagues with a personality disorder
}

\begin{abstract}
People with mental disorders, especially personality disorders, often face low acceptance at work. This is particularly problematic when returning to work after sick-leave, because it impedes reintegration into the former workplace. This study explores colleagues' reactions towards a problematic worker dependent on the returning person's reintegration strategy: The returning person undertaking changes in their behaviour is compared with the person requesting adjustments of the workplace. In an experimental study 188 employed persons read one of four vignettes that described a return-to-work-situation of a problematic co-worker. Across all vignettes the co-worker was depicted as having previously caused problems in the work team. In the first vignette the co-worker asked for workplace-adjustments when she returned to work; in the second, she attempted to change her behaviour in order to cause less problems; the third vignette combined both workplace-adjustments and behavioural changes; and the fourth (control) vignette did not include any change. Study participants were asked for their reactions towards the problematic co-worker. Vignettes that included a behavioural change evoked more positive reactions towards the co-worker than vignettes without any behavioural change. Asking for workplace-adjustments alone did not yield more positive reactions compared to not initiating any change. When preparing employees with interactional problems for their return to work, it is not effective to only instruct them on their statutory entitlement for workplace-adjustments. Instead, it is advisable to encourage them to proactively strive for behaviour changes.
\end{abstract}




\section{Key terms}

Workplace; personality disorders; mental health; sick-leave; acceptance; social distance 


\section{Introduction}

Thirty per cent of the general population suffer from mental disorders (Wittchen et al., 2011). For employees, mental disorders often involve numerous problems that can result in prolonged sick-leave or even disability (Persson, Benfort, Wahlin, \& Ekberg, 2014; Sado et al., 2014). Especially personality disorders typically entail maladaptive interactional behaviour (Cramer \& Davidhizar, 2000). Therefore, individuals suffering from personality disorders easily evoke negative reactions from colleagues and supervisors, and as a result, they experience elevated levels of conflicts at work (Ettner, MacLean, \& French, 2011; Hengartner, Müller, Rodgers, Rössler, \& Ajdacic-Gross, 2014; Baumann, 2007). Overall, individuals affected by personality disorders have a higher risk of being laid off (Ettner et al., 2011), and of receiving a disability pension (Ostby et al., 2014). With an overall prevalence of about 15\% in the general population (Ettner et al., 2011), personality disorders are a relevant mental health problem for the workforce.

One situation in which reactions of colleagues and supervisors are of particular importance is when returning to work after sick-leave. An appropriate reintegration strategy on the part of the returning individual may facilitate or hinder effective reintegration. The present study seeks to identify with which strategy a "problematic co-worker", who suffers from a personality disorder, may bring about more positive reactions by colleagues. Research suggests that adjustments of the workload and -role, more supervision and the provision of access to counselling may support reintegration (Henderson, Williams, Little, \& Thornicroft, 2013). However, it is not clear whether this is the best strategy.

According to expectation theory (Burgoon, 1993), there may be a normative expectation towards the returning colleague to help solving problems, and not only to ask for help. Thus, employees with a personality disorder who return to work can choose one of two strategies or a combination of both; they might ask to get their workplace adjusted to their particular impairments; or they might signal their readiness to work on their own capabilities and 
behaviour in order to help preventing conflicts and compensate for dysfunctional behaviour (Baltes \& Dickson, 2001); or they might employ both strategies. The goal of this study is to test which strategy results in more positive reactions from colleagues.

\section{Methods}

\section{Study design and procedure}

We conducted an experiment with two fully crossed factors $(2 * 2$ factorial design) using case vignettes. The vignettes described a return-to-work-situation of a female problematic colleague with an anancastic personality disorder (Table 1). In the vignettes, the returning colleague either announced behavioural changes to achieve improvements of her problems, or did not do so (=Factor 1, 2 levels); or she requested workplace-adjustments, or did not do so (=Factor 2, 2 levels). The fully crossed design resulted in four conditions, operationalized with the following four case vignettes: 1) the problematic co-worker asked for workplaceadjustments, 2) she initiated efforts to change her own behaviour, 3) she requested workplaceadjustments and showed efforts for behavioural changes, 4) control condition with no change.

[insert table 1 about here]

Study participants were randomly assigned to one of the four conditions. After reading the case vignette, participants were asked for their reactions and behavioural intentions towards the "problematic co-worker" (see Questionnaire and measures) in case they should work together with her in a team.

In order to explore factors of potentially additional influence (Vornholt, Uitdewilligen, \& Nijhuis, 2013), we assessed study participants' age, gender, whether personally affected by mental health problems, and personality traits according to the Big Five (Rammstedt \& John, 2005). 


\section{Questionnaire and measures}

The reactions towards the problematic co-worker were operationalized with self-rating measures of social distance, perception of similarity, and positive and negative affective reactions. Items assessing social distance and perception of similarity were developed for the present study (Table 2); they build upon well established psychological concepts (e.g. Baumann, 2007; Ensher, Grant-Vallone, \& Marelich, 2002) and showed good internal consistency (Table 3).

[insert table 2 about here]

Affective reactions were assessed with the German PANAS scale (Krohne, Egloff, Kohlmann, \& Tausch, 1996). Positive and negative affective reactions are measured with ten items, respectively.

After reading the case vignette, participants were asked to imagine that "Mrs. K." had returned to work and that the participant's job required working closely with her. Participants should then report their perceived social distance and similarity perceptions and their own affective reaction (PANAS) when thinking about this situation. Finally, participants provided demographic and work-related information and personality characteristics (Rammstedt \& John, 2005).

\section{Participants}

We obtained data from a random sample of German employees via public online networks.

There were 719 clicks counted for viewing the questionnaire. Including only employed individuals with complete data in the analysis resulted in a sample size of $n=188$. 
The average age of the participants was 34.92 years $(S D=10.24), 66.5 \%$ of whom were women. $3.2 \%$ were unskilled workers, $40.7 \%$ had completed an apprenticeship, $56.1 \%$ held a university degree. All participants were presently employed and worked on average 39.1 hours a week $(S D=8.9) .90 .7 \%$ occupied a not-physically demanding job, $66.0 \%$ mainly worked in teams, $41.8 \%$ had a leadership position. $30.9 \%$ were presently or had earlier been affected by a mental disorder. The sample is therefore representative concerning the general mental health epidemiology (Wittchen et al., 2011). On average participants had work experience of 12.4 years $(S D=10.7)$. Sample characteristics were equally distributed over the four conditions, indicating that the randomization was performed sufficiently.

\section{Statistical analyses}

Effects were tested with a multivariate analysis of (co)variance (MANCOVA, SPSS version 22). In order to explore other potentially influencing factors, an additional regression analyses was performed.

\section{Results}

The multivariate effect showing efforts for a behavioural change (Factor 1) was significant (Pillai's Trace $=.083, F(4,178)=4.02, p<.01)$. Univariate tests indicate that the conditions in which the problematic colleague showed efforts for changing her own behaviour (in contrast to showing no such effort) evoked significantly lower social distance and higher positive affect in the respondent (Table 3). In contrast, the multivariate effects of asking for workplace-adjustments (Factor 2) or the combination of both conditions (Factor 1 x Factor 2) were not significant; this applies also to all univariate effects.

[insert table 3 about here] 
An additional exploratory linear regression analyses considering additional potential predictors ${ }^{1}$ shows that a higher score in agreeableness ( $b e t a=-.233, p=.002$ ) was associated with lower social distance towards the problematic co-worker.

\section{Discussion}

Workplace adjustments, e.g. reduced workload or responsibilities, and social support at work represent important factors for facilitating return to work of employees with mental disorders (Andersen, Nielsen, \& Brinkmann, 2012). The present study, however, showed that efforts on the part of the problematic colleague result in more positive reactions towards him or her. Therefore, only asking for workplace-adjustments without signalizing personal initiative (Frese \& Fay, 2001) in terms of efforts for changing one's behaviour may not be the optimal way when seeking acceptance and more positive reactions at work.

Whereas the present results are important from a practical point of view, it will be a challenge to make them known to the stakeholders who have to apply them. A recent study showed that employers are still fairly poorly informed. Not even half of a sample of interviewed employers (39\%) had a formal strategy on how to deal with mental health issues at the workplace, and $44 \%$ of the employers believed that employees suffering from mental health problems were able to work effectively at all times (Henderson et al., 2013). Taking this and our results into account, the following advice can be given: Employees with mental disorders, which are usually associated with "problems" at work, should be taught not (only) to "fight for their rights" and request workplace-adjustments according to the law, but to actively take part in their return-to-work process (Frese \& Fay, 2001) and make their efforts visible to co-workers and supervisors.

\footnotetext{
${ }^{1}$ Variables included in the exploratory regression analysis were: age, gender, being affected by a mental disorder oneself, condition active or passive behaviour, condition workplace adjustment or not, and the Big Five. $R^{2}=.143, p=.004, n=173$.
} 
Our exploratory regression analyses showed that higher agreeableness was associated with lower social distance. Colleagues with higher agreeableness may have a higher tolerance for the peculiar behaviours that individuals with personality disorders sometimes show (Butrus \& Witenberg, 2012).

As a limitation, the data collected in this study is not based on behavioural observation. Reactions in real settings might differ from what participants suggested in their ratings. Furthermore, initial acceptance may change when old problems start reoccurring.

Further research should test the extent to which the present results generalize to other mental disorders, other work-related behavioural problems, and whether length of "problem history at work" mitigates the effect found here. Furthermore, the role of supervisors should be explored in more depth. Employers who oversaw employees with mental health problems reported closer non-work social contact, i.e., lower social distance (Brohan et al., 2012). They also had a better knowledge concerning the law and had a more accepting policy with regard to hiring "applicants with disabilities" than employers who had no employees with mental disorders. Future research should investigate whether well-informed supervisors are more effective in choosing problem-solving strategies that makes working with "problematic" employees more effective (e.g. Cramer \& Davidhizar, 2000).

\section{Conflict of interest statement:}

There are no conflicts of interest. 


\section{References}

Andersen, M. F., Nielsen, K. M., \& Brinkmann, S. (2012). Meta-synthesis of qualitative research on return to work among employees with common mental disorders. Scandinavian Journal of Work, Environment \& Health, 38, 93-104.

Baltes, B. B., \& Dickson, M. W. (2001). Using life-span models in industrial-organizational psychology: The theory of selective optimization with compensation. Applied Developmental Science, 5, 51-62.

Baumann, A. E. (2007). Stigmatization, social distance and exclusion because of mental illness: The individual with mental illness as a "stranger". International Review of Psychiatry, $19,131-135$.

Burgoon, J. K. (1993). Interpersonal expectations, expectancy violations, and emotional communication. Journal of Language and Social Psychology, 12, 30-48.

Brohan, E., Henderson, C., Wheat, K., Malcom, E., Clement, S., Barley, E.A., Slade, M., \& Thornicroft, G. (2012). Systematic review of beliefs, behaviours and influencing factors associated with disclosure of a mental health problem in the workplace. BMC Psychiatry, 12: 11.

Butrus, N., \& Witenberg, R.T. (2012). Some Personality Predictors of Tolerance to Human Diversity: The Roles of Openness, Agreeableness, and Empathy. Australian Psychologist, 48, 290-298.

Cramer, C., \& Davidhizar, R. (2000). The health care employee with an "attitude". Hospital Materiel Management Quarterly, 22, 27-33. 
Ensher, E.A., Grant-Vallone, E.J., \& Marelich, W.D. (2002). Effects of perceived attitudinal and demographic similarity on protégés support and satisfaction gained from their mentoring relationships. Journal of Applied Social Psychology, 32, 1407-1430.

Ettner, S.L., MacLean, J.C., \& French, M. (2011). Does having a dysfunctional personality hurt your career? Axis II personality disorders and labor market outcomes. Industrial Relations (Berkeley), 50, 149-173.

Frese, M., \& Fay, D. (2001). Personal initiative: an active performance concept for work in the $21^{\text {st }}$ century. Research in Organizational Behaviour, 23, 133-187.

Henderson, C., Williams, P., Little, K., \& Thornicroft, G. (2013). Mental health problems in the workplace: changes in employers' knowledge, attitudes and practices in England 20062010. British Journal of Psychiatry Supplement, 55, 70-76.

Hengartner, M.P., Müller, M., Rodgers, S., Rössler, W., \& Ajdacic-Gross, V. (2014).

Occupational functioning and work impairment in association with personality disorder traitscores. Social Psychiatry and Psychiatric Epidemiology, 49, 327-335.

Krohne, H. W., Egloff, B., Kohlmann, C.-W., \& Tausch, A. (1996). Untersuchungen mit einer deutschen Version der "Positive and Negative Affect Schedule" (PANAS) [Investigations with a German version of the Positive and Negative Affect Schedule]. Diagnostica, 42, 139156.

Ostby, K.A., Czajkowski, N., Knudsen, G.P., Ystrom, E., Gjerde, L.C., Kendler, K.S., Orstavik, R.E., \& Reichborn-Kjennerud, T. (2014). Personality disorders are important risk factors for disability pensioning. Social Psychiatry Psychiatric Epidemiology, 49, 2003-2011. 
Persson, J., Bernfort, L., Wahlin, C., \& Ekberg, K. (2014). Costs of production losses and primary health care interventions for return-to-work of sick-listed workers in Sweden. Disability and Rehabilitation, 24, 1-6.

Rammstedt, B., \& John, O.P. (2005). Kurzversion des Big Five Inventory (BFI-K):

Entwicklung und Validierung eines ökonomischen Inventars zur Erfassung der fünf Faktoren der Persönlichkeit [Short version of the Big Five Inventory (BFI-K): Development and validation of an economic inventory for assessment of the five factors of personality]. Diagnostica, 51, 195-206.

Sado, M., Shirhase, J., Yoshimura, K., Miura, Y., Yamamoto, K., Tabuchi, H., \& Kato, M. (2014). Predictors of repeated sick-leave in the workplace because of mental disorders, Neuropsychiatric Disease and Treatment, 29, 193-200.

Vornholt, K., Uitdewilligen, S., \& Nijhuis, F.J.N. (2013). Factors Affecting the Acceptance of People with Disabilities at Work: a Literature Review. Journal of Occupational Rehabilitation, 23, 463-475.

Wittchen, H.U., Jacobi, F., Rehm, J., Gustavsson, A., Svensson, M., Jönsson, B., Olesen, J., Allgulander, C., Alonso, J., Faravelli, C., Fratiglioni, L., Jennum, P., Lieb, R., Maercker, A., van Os, J., Preisig, M., Salvador-Carulla, L., Simon, R., \& Steinhausen, H.C. (2011). The size and burden of mental disorders and other disorders of the brain in Europe 2010. European Neuropsychopharmacology, 21, 655-679. 
Table 1. Case vignettes of a problematic co-worker with an anancastic personality disorder in different conditions: with "behavioural changes" and "workplace-adjustments"

Introduction (the same across all conditions)

Mrs. K. is a 32-year-old colleague of yours who returns to your team after sickness leave. She was in treatment because of a mental disorder. Before her absence, Mrs. K. had been extremely conscientious and almost pedantic at work. She had had difficulties in completing her assignments because she was never satisfied with the results. Repeatedly, she checked her own work and that of her colleagues for mistakes. This led to delays in work processes. You told her several times to timely pass on information to other colleagues. In meetings she impeded progress by talking about unimportant details. At the same time she was not able to make important decisions. You and your colleagues were annoyed by this and felt hindered in completing your jobs. Three months ago, Mrs. K. was at a total loss and unable to cope anymore, so that she finally filed for sick-leave.

Return to work - Condition 1: No changes at all (Control condition)

Now Mrs. K. is returning to your team. She still appears extremely conscientious and too focused on details. Interacting with her is tiring and demanding. Mrs. K. shall continue working with you and your colleagues in the same office and on group tasks.

\section{Return to work-Condition 2: Workplace-adjustment}

Now Mrs. K. is returning to your team. She still appears extremely conscientious and too focused on details. Interacting with her is tiring and demanding. She states that on the basis of the social law she has applied for workplace-adjustments; according to the law, the employer is obliged to give her an accessible workplace in which she can do her work without problems. The supervisor has already agreed to assign some of her jobs to the team in order to prevent further delays. Mrs. K. shall continue working with you and your colleagues in the same office and on group tasks. 
Return to work-Condition 3: Behavioural change

Now Mrs. K. is returning to your team. She still appears extremely conscientious and too focused on details. Interacting with her is tiring and demanding. Mrs. K. states that she knows about her behavioural problems and that she is willing to work on herself in order to avoid delaying work processes up from now. She was not yet perfectly sure whether it will always work out, as in some work aspects conscientiousness is required. She is now attending a time management course. You have seen that Mrs. K. has put a list with important rules on how to make decisions next to her computer. Mrs. K. shall continue working with you and your colleagues in the same office and on group tasks.

Return to work-Condition 4: Workplace-adjustment and behavioural change

Now Mrs. K. is returning to your team. She still appears extremely conscientious and too focused on details. Interacting with her is tiring and demanding. She reports that on the basis of the social law she has applied for workplace-adjustments: According to the law, the employer is obligated to give her an accessible workplace in which she can do her work without problems. The supervisor has already agreed to assign some of her work duties to the team in order to prevent further delays. Mrs. K. shall continue working with you and your colleagues in the same office and on group tasks. Mrs. K. reports that she knows about her behavioural problems and that she is willing to work on herself in order not to delay work processes up from now. She was not yet perfectly sure whether it will always function, as in some work aspects conscientiousness is required. She is now attending a time management course. You have seen that Mrs. K. has put a list with important rules on how to make decisions next to her computer. Mrs. K. shall continue working with you and your colleagues in the same office and on group tasks.

Closure (the same across all conditions)

This way, work appears to be manageable for you and your colleagues. But it is clear that 
from time to time there will be problems with Mrs. K.

Table 2. Items of the two main outcome variables "social distance" and "similarity perception"

Social distance towards the problematic co-worker

I would rather ask someone else for advice than Mrs. K.

Mrs. K. is the type of person I would normally avoid.

I would rather spend as little time with Mrs. K. as necessary.

I would dislike working with Mrs. K.

I would dislike helping Mrs. K. at work.

I would dislike passing my breaks with Mrs. K.

Mrs. K. is unlikeable to me.

In case I had a say in personal decisions, I would suggest taking Mrs. K. out of the team.

Similarity perception towards the problematic co-worker

Mrs. K. seems to be similar to me.

Mrs. K. and I have a couple of things in common.

Mrs. K. and I have similar personalities.

If I was ill, would behave similarly to Mrs. K. 
Table 3. Comparison of degree of perceived social distance, similarity and affective reaction in a $2 * 2$-design of conditions of "behavioural changes" and "workplace-adjustments". Means (standard deviation) are reported $(N=188)$. Multivariate analysis of variance with test of significances for main and interaction effects.

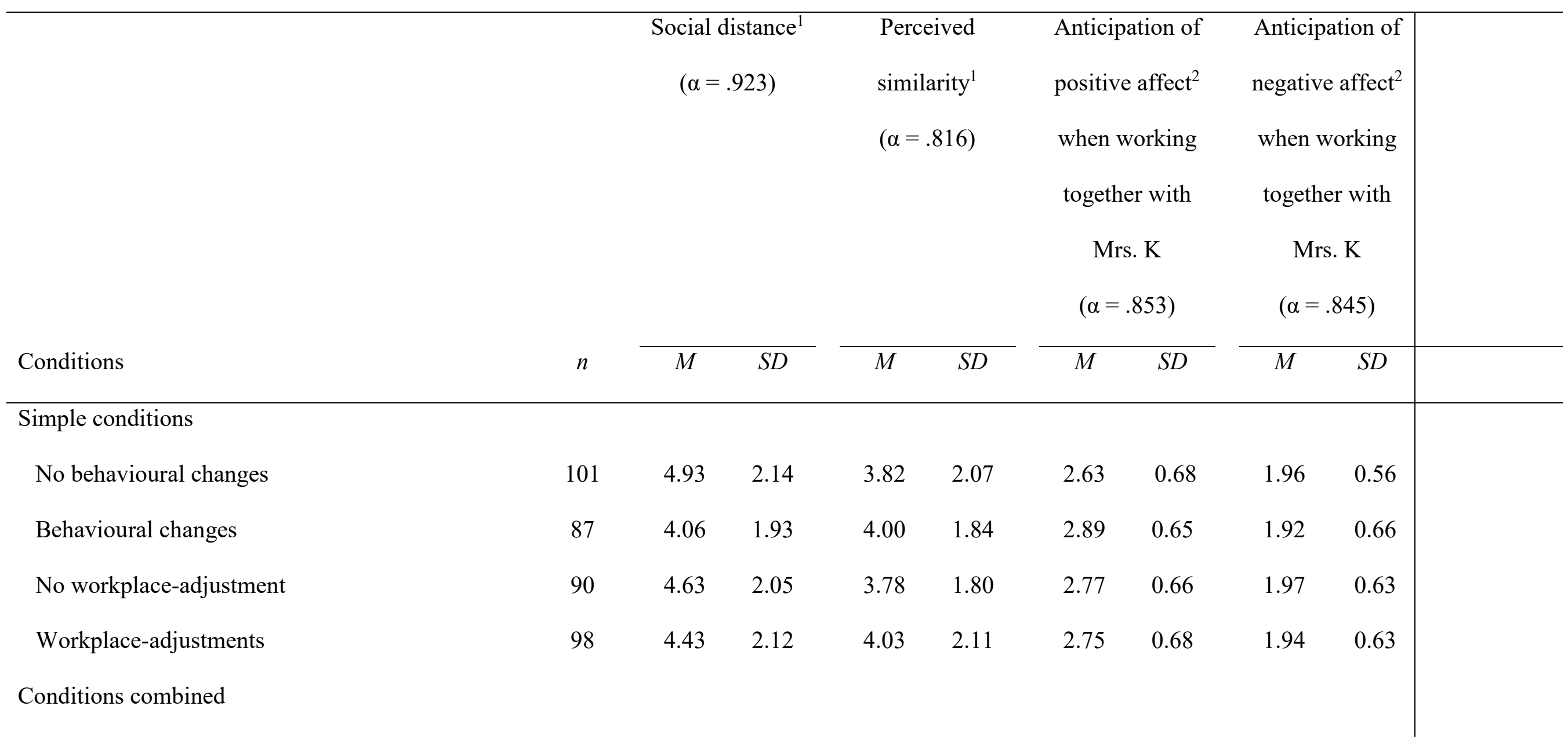




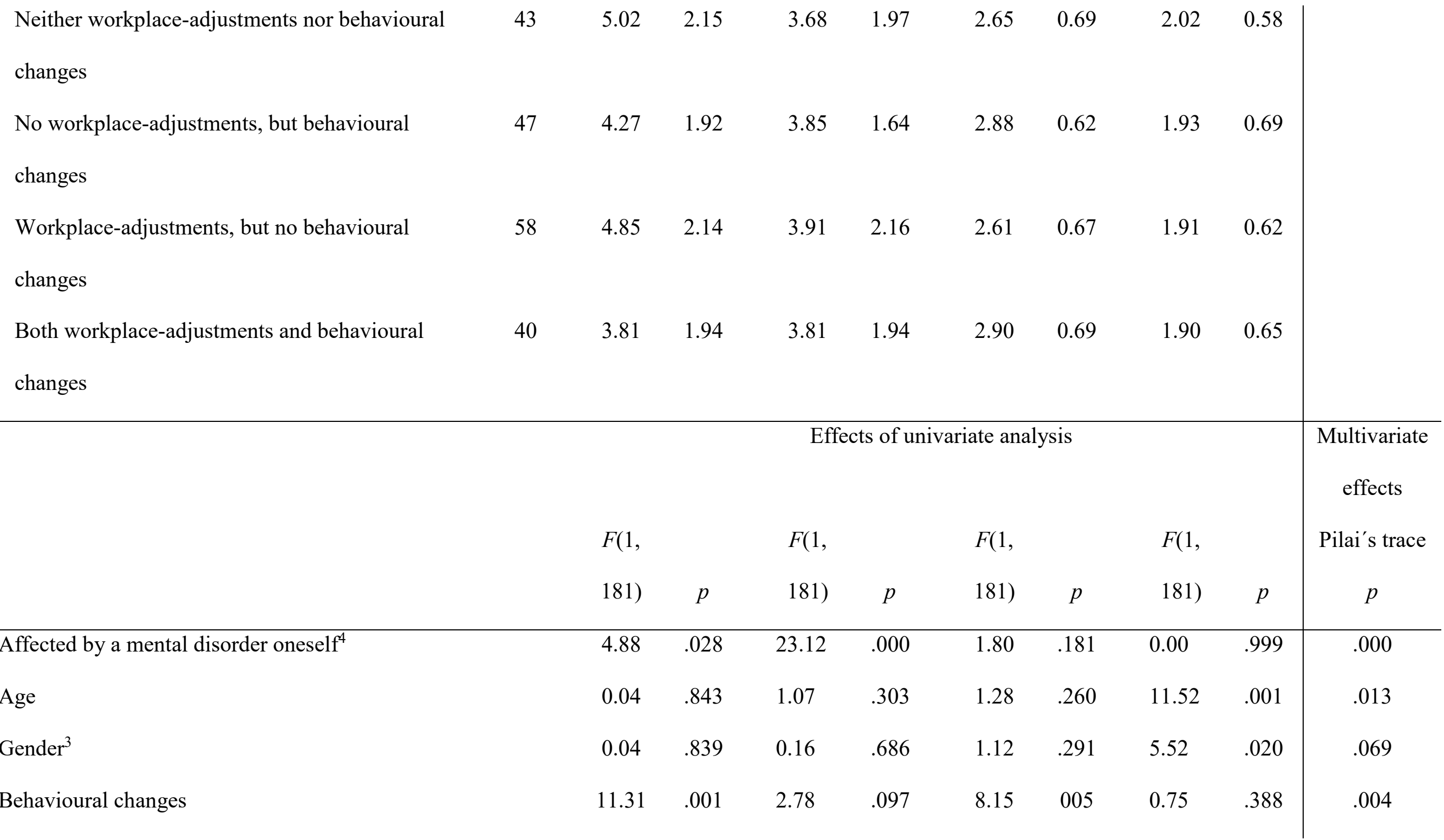


Workplace-adjustments

Behavioural changes x workplace-adjustments

$\begin{array}{ll}1.39 \quad .240 \\ 0.07 & .709\end{array}$

$0.07 \quad .709$

$1.61 \quad .207$
0.10

0.10

.747
.814

0.44

0.28

0.00

.970

0.28
Note: ${ }^{1}=$ Items were rated on a 10 point Likert scale from $1=I$ do not agreement at all to $10=$ I agree fully. ${ }^{2}=$ Items were rated from $1=$ not at all to $5=$ extremely $^{3}=$ Gender: $1=$ female, $2=$ male $.^{4}=$ Affected by mental disorder: $1=$ no or $2=$ yes. 